\title{
Prevalence of Fruit and Vegetable Consumption and Physical Activity by Gender and Race/Ethnicity - California, 2005-2006
}

\author{
Joan Faith Epstein ${ }^{1,2}$, Sharon B. Sugerman ${ }^{2,3}$, Patrick Mitchell ${ }^{2,3}$, and Marta Induni ${ }^{4}$ \\ Survey Research Group, Cancer Surveillance \& Research Branch ${ }^{1}$, \\ California Dept of Public Health, Public Health Institute ${ }^{2}$, \\ Network for a Healthy California, Cancer Control Branch ${ }^{3}$, and \\ Mathematica, Policy Research Inc. ${ }^{4}$
}

\begin{abstract}
Diets high in fruits and vegetables and participation in regular physical activity are associated with a lower risk for several chronic diseases and conditions. The present study analyzed the combined prevalence of these two activities by race/ethnicity and gender among adults in California and among adults in California at or below $130 \%$ of the federal poverty level (FPL), using self-reported data from the 2005 and 2006 California Behavioral Risk Factor Surveillance System (BRFSS).

Findings for California were similar to findings for the nation, showing gender and racial/ethnic differences for each of these variables, singly and in combination. Also, low-income men had a significantly lower prevalence of goal-level fruit and vegetable consumption than did low-income women.

Although some demographic disparities are evident among Californians, the prevalence of achievement of two key healthy lifestyle behaviors concurrently remains quite low. These results emphasize the need for promoting diets high in fruits and vegetables and regular physical activity among all Californians.
\end{abstract}

(C) 2008 Californian Journal of Health Promotion. All rights reserved.

Keywords: diet, fruits and vegetables, physical activity, race, gender, poverty

\section{Introduction}

Adequate consumption of fruit and vegetables and regular physical activity are two key lifestyle behaviors that reduce risk of obesity and chronic disease. Fruit and vegetable consumption is associated with reduced risk for heart disease (He et al, 2007), hypertension, (Svetkey et al, 1999) stroke (Dauchet, 2005), many cancers (World Cancer Research Fund/American Institute for Cancer Research, 2007), vision problems associated with aging (Cho, 2004), possibly diabetes (Montonen, 2005) and weight reduction (National Center for Chronic Disease Prevention and Health Promotion, 2006). Evidence demonstrates that, compared to those who are less active, more active men and women have lower rates of allcause mortality, coronary heart disease, high blood pressure, stroke, type 2 diabetes, metabolic syndrome, colon cancer, breast cancer, and depression, than those who do not (Physical Activity Guidelines Advisory Committee, 2008).

Disparities in each of these behaviors are found among different racial/ethnic groups and persons of different income levels. Disparity results are not consistent for fruit and vegetable consumption, depending on how it is evaluated. Based on national findings from the Behavioral Risk Factor Surveillance System (BFSS), women report consuming fruit and vegetables more times daily than men. Non-Hispanic White and Multiracial/Other respondents report consuming vegetables more often than nonHispanic Black respondents who, in turn, consume them more often than Hispanic 
respondents. (Note "Multiracial /Other" refers to Asian, Hawaiian, Pacific Islander, Native American, Alaska Native, and persons of multiple race as reported by the National Center for Chronic Disease Prevention and Health Promotion (CDC)).

Racial/ethnic patterns are different for fruit, with non-Hispanic White respondents lower than the other three groups, which do not differ from one another. Income less than $\$ 50,000 /$ year was associated with less frequent consumption of both fruit and vegetables. (Blanck et al, 2007). However, National Health Interview Survey (NHIS) findings are quite different, with men averaging about one serving a day more than women, and Hispanic respondents consuming significantly more fruits and vegetables than non-Hispanic White, non-Hispanic Black, and Other respondents. Women of income level 350 percent of the Federal Poverty Level (FPL) and higher consume more total fruit and vegetables than lower income women, although there is no income effect for men (Thompson et al, 2005). For the California Health Interview Survey (CHIS) results, the pattern was similar to NHIS-men report consuming five or more servings a day more than women. Non-Hispanic White and Hispanic respondents report greater consumption than non-Hispanic Black or Asian Californians, and those at the highest income bracket $(300 \%$ FPL or greater) reported consuming at least five servings of fruits and vegetables more often than those in the lowest bracket (less than 100\% FPL) (Holtby, 2008).

Compared to women, men are more likely to get sufficient regular physical activity for good health, and white men are more likely to do so than men from other racial/ethnic groups. Women show greater ethnic disparities, with white women at highest prevalence, followed in descending order by Other, Hispanic, and Black women (Kruger and Miles, 2007). Low-income persons demonstrate lower physical activity levels than higher income individuals (Centers for Disease Control and Prevention, 2009). However, we are not aware of any papers that describe disparities of the combined prevalence of meeting diet and physical activity recommendations, except a study in the April 6,
2007 Morbidity and Mortality Weekly Report (MMWR) that analyzed the combined prevalence of: 1) consumption of fruits and vegetables five or more times per day and 2) regular physical activity by race/ethnicity and sex using the 2005 BRFS (Kruger et al., 2007). The study found racial/ethnic differences in combining these two behavioral variables among men and women. Men of multiple/other races had a significantly higher prevalence of combining the two variables than did nonHispanic White men. Non-Hispanic Black and Hispanic women had significantly lower prevalence of combining the two variables than non-Hispanic white women.

We were also not aware of any study presenting data on the combined prevalence of these two variables for the state of California. California has a reputation as a healthy lifestyle state, and has a different racial/ethnic composition than the United States as a whole (U.S.Census Bureau, 2009). For this reason, we replicated the Kruger study with the California population, using the 2005 and 2006 California Behavioral Risk Factor Surveillance System (BRFSS), to analyze the combined prevalence of both behaviors by race/ethnicity and sex among adults in California. In addition we analyzed these two activities by race/ethnicity and sex for adults at or below $130 \%$ of the federal poverty level (FPL), and compared them to adults in California living in households with income above $130 \%$ of the FPL. The $130 \%$ FPL measure was constructed from the household size and household income criteria listed in the Federal Register (2006). The cut point "at or below 130\% FPL" was used because it is the upper boundary of qualifying household income for the federal Food Stamp Program.

The prevalence of these behaviors at or below this poverty level cut point was of particular interest to the authors. Two of the authors (P.M. and S.B.S.) are on staff of California's Network for a Healthy California, the largest provider of Food Stamp Nutrition Education in the nation. The Network's interventions primarily target low-income women, and it has been in operation in California since 1997. Its activities combine a social marketing approach that includes mass 
media with community events and direct education to promote increasing fruit and vegetable consumption and physical activity. Among other Network activities directed towards adults, there are targeted campaigns for Latinos and African Americans, as well as programs in the retail setting and in worksites.

\section{Methods}

\section{Data Source}

This study used self-reported data from the 2005 and 2006 California Behavioral Risk Factor Surveillance System (BRFSS), which was approved by the Committee for the Protection of Human Subjects (the Internal Review board) for the California Department of Public Health. The California BRFSS is an ongoing effort by the California Department of Public Health in conjunction with the United States Centers for Disease Control and Prevention (CDC) to assess the prevalence of and trends in health-related behaviors in the California population aged 18 years and older. It uses a random-digit-dialed telephone survey of the non-institutionalized civilian population in California aged $>18$ years. The questionnaire is developed each year by the Center for Disease Control (CDC) in collaboration with participating state programs. Wherever possible, questions have been selected from previously conducted national surveys for comparability. Interviews are conducted by trained interviewers following standardized procedures developed by the CDC.

In 2005 and 2006, the survey used a stratified, multistage probability sampling design. It was administered to $\mathrm{N}=6,098$ persons in 2005 and $\mathrm{N}=5,692$ persons in 2006. The response rate, which indicated the proportion of eligible households contacted which resulted in a completed interview, was $66 \%$ for 2005 and 65\% for 2006 (American Association of Public Opinions Research guidelines (AAPOR), 2006)).

\section{Comparisons with CDC Study}

The methods for the present study for the state of California are similar to the 2007 CDC study. However, there were some differences. Due to the smaller sample size for the state, instead of one year of data, this study aggregated the data from the 2005 and 2006 BRFSS. Instead of the six race/ethnicity categories used in the study for the United States, this study used four race/ethnicity categories among all persons. In addition this study included an analysis of persons at or below $130 \%$ of the FPL and compared them to Californians living in households with incomes above $130 \%$ of the FPL.

\section{Measures and Variables}

The four racial/ethnic categories included in this report for the population of California were: non-Hispanic white (white), non-Hispanic Black (Black), Hispanic, and Other Ethnic. Other Ethnic included American Indian/Alaska Native (AI/AN) (12.6\%), Asian/Pacific Islander (A/PI) $(83.4 \%)$, and multiracial/other $(4.0 \%)$. (Kruger, 2008; Thompson, 2005)

The two racial/ethnic categories for persons residing in California at or below 130\% FPL were White and non-White. Any respondent who reported being of Hispanic ethnicity was categorized as Hispanic regardless of race.

To measure consumption of fruits and vegetables, respondents were asked six questions: "How often do you drink fruit juices such as orange, grapefruit, or tomato?" "Not counting juice, how often do you eat fruit?" "How often do you eat green salad?" "How often do you eat potatoes, not including French fries, fried potatoes, or potato chips?" "How often do you eat carrots?" and "Not counting carrots, potatoes, or salad, how many servings of vegetables do you usually eat?" Respondents answered in terms of per day, week, month, or year, as preferred. The respondents were classified as eating or not eating fruits and vegetables five or more times (not servings) per day.

Moderate activities included "brisk walking, bicycling, vacuuming, gardening, or anything else that causes small increases in breathing or heart rate," while vigorous activities included "running, aerobics, heavy yard work, or anything else that causes large increases in breathing or heart rate." To measure physical 
activity, respondents were asked the following three questions for activities of moderate intensity and again for activities of vigorous intensity: 1) In a usual week did you engage in these physical activities for at least 10 minutes at a time, 2) How many days in a week did you engage in these activities at least 10 minutes at a time 3) On days when you did these activities how much total time per day did you spend on doing these activities. To match the classifications used by Kruger and colleagues (2007), respondents were classified as being regularly active if they reported engaging in moderate-intensity activity at least 30 minutes per day, five or more days per week, or vigorous-intensity activity at least 20 minutes per day, three or more days per week. Respondents were classified as insufficiently active if they reported engaging in any physical activity for at least 10 minutes per week, but did not meet the requirements for regular activity. Respondents who reported no instances of physical activity of at least 10 minutes' duration during a usual week were classified as inactive.

A combined variable was created which classified respondents into four categories: 1) those who ate fruits and vegetables five or more times per day and were regularly active 2) those who ate fruits and vegetables five or more times per day but were not regularly active 3) those who did not eat fruits and vegetables five or more times per day and were regularly active and 4) respondents who did not eat fruits and vegetables five or more times per day and were not regularly active.

\section{Statistical Analysis}

This study used descriptive statistics such as percentages to study the combined prevalence of: 1) consumption of fruits and vegetables five or more times per day and 2) regular physical activity. Age-adjusted prevalence was stratified by sex and race/ethnicity.

To take into account that the probability of selection is different for different households, all estimates were weighted to the respondents' probabilities of being selected. Since the sample for each year was a probability sample for the adult population of California, weights could be adjusted to account for combining two years of data. To adjust for age, race and sex differences between the BRFS sample and the California population, the data was weighted according to the age-, race-, and sex-specific data for California from the 2000 Census.

Respondents missing information for an item were defined as missing in any analysis involving that item. Because of this, the sample size varied depending upon the items in the analysis. The sample size was 9,899 for the analysis including fruits and vegetable consumption but not physical activity, and 10,379 for the analysis including physical activity but not fruits and vegetable consumption, and 9,801 for the analysis including both physical activity and fruit and vegetable consumption. This sample consisted of 6,471 White, 411 Black, 2,268 Hispanic and 652 Other Ethnic respondents. There were 1,566 participants in the final study sample for the low income group ( $\leq 130 \%$ FPL) consisting of 482 White and 1,084 non-White respondents and there were 7,569 participants in the higher income group (> 130\% FPL) consisting of 5,518 White and 2,051 non-White respondents.

All standard errors were calculated using the SURVEYFREQ (SAS), statistical software programs that use the Taylor series expansion method to estimate sampling errors of estimates based on complex sample designs (SAS Institute Inc., 2007). Chi-square tests were used to compare Californians living in households with income at or below $130 \%$ of the FPL to those with incomes above $130 \%$ of the FPL. All pairs of subpopulations by sex and race/ethnicity were tested for statistical significance with t-tests using the DESCRIPT procedure in SUrvey DAta ANalysis (SUDAAN), a statistical software program that also uses a Taylor series expansion method to adjust for the complex sample design (Shah et al, 1996). Significance was reported for p-values $\leq .05$.

\section{Results}

The sample distribution by age, race and sex are given in Table 1. Rates for eating fruits and vegetables five or more times per day, regular 
physical activity and the combination of these behaviors for the total population of California are given in Table 2. During 2005-2006, the estimated prevalence of eating fruits and vegetables five or more times per day was $26.6 \%$, and was significantly lower for men than women. This difference between men and women was also significant among White $(18.8 \%$ vs. $29.9 \%)$ and Hispanic $(17.9 \%$ vs. $35.3 \%)$ respondents. The prevalence of eating fruits and vegetables five or more times per day was significantly lower among White men (18.8\%) and Hispanic men (17.9\%) compared to Other ethnic men (37.7\%). Among women there were no statistically significant differences among race/ethnicities in the prevalence of eating fruits and vegetables five or more times per day.

Among the total sample, $52.7 \%$ engaged in regular physical activity. This rate was higher among White than among Hispanic respondents $(58.5 \%$ vs. $45.6 \%)$. Among Black and Other Ethnic respondents, regular physical activity was about twice as prevalent among men as women. Black men were significantly more likely to engage in regular physical activity than White men $(79.8 \%$ vs. $56.7 \%$ ), but White men were significantly more likely to engage in physical activity than Hispanic men (43.5\%). Among women, the prevalence of regular physical activity was highest among White women $(60.1 \%)$, and this rate was significantly higher than the rate for other racial/ethnic groups.

The combined prevalence for achieving both behaviors, eating fruits and vegetables five or more times per day and engaging in regular physical activity was $16.3 \%$. This prevalence was higher for women than men among the total population of California, particularly among White Californians $(21.4 \%$ vs. $12.4 \%$ respectively). Although not statistically different, the prevalence of these two behaviors was $26.2 \%$ for Other ethnic men and $9.5 \%$ for Hispanic men. Among women the prevalence of reaching both goals was significantly higher for White than for Black women).

Among the total sample, $36.4 \%$ did not engage in either of these two behaviors. This rate was significantly higher for Hispanic than Black Californians. Among Black respondents, the prevalence was significantly higher for women than men (38.2\% vs. $16.3 \%)$ while among Hispanics it was significantly higher for men than women (47.3\% vs. $33.2 \%)$. Among males, Hispanic men (47.3\%) had a significantly higher rate of not engaging in either of the two behaviors than did Black men (16.3\%) and Other ethnic respondents $(23.3 \%)$; White men also had significantly higher rates than Black men. Among females, there were no significant differences among the races.

Rates for these activities for respondents at or below $130 \%$ of the poverty level are given in Table 3. Among low-income persons, $33.4 \%$ ate fruits and vegetables at least five times per day. For these Californians, the prevalence was also significantly lower for men $(25.7 \%)$ than for women $(41.4 \%)$. Among the total low-income sample, $46.6 \%$ reported regular physical activity, with no gender-related differences. For the total low-income sample of males, there were no significant differences on fruit and vegetable intake or physical activity among the racial/ethnic groups. White women were significantly more likely to engage in regular physical activity than non-White women, but differences in fruit and vegetable consumption between these two groups was not significant.

Rates for the consumption of fruits and vegetables five or more times per day and/or regular physical activity for California adults with incomes above $130 \%$ FPL are given in Table 4. These rates were similar to the rates for the total adult population of California. However, there were differences between reported fruit and vegetable consumption rates for those with incomes at or below $130 \%$ of the FPL and those with incomes above $130 \%$ of the FPL. Persons with incomes at or below 130\% FPL were significantly more likely to report eating fruits and vegetables five or more times per day than those with incomes above the $130 \%$ FPL (33.4\% vs. $24.2 \%)(\mathrm{p} \leq 05)$. This was also true among adult California females in general $(41.4 \%$ vs. $29.1 \%)(\mathrm{p} \leq .05)$ and non-White adult California females (44.7\% vs. $29.2 \%)$ (p $\leq$ $.05)$. There were no other statistically significant 
differences between those above and below $130 \%$ of the FPL for eating fruits and vegetables five or more times per day and or regular physical activity.

\section{Discussion}

This report describes gender differences and racial/ethnic differences by gender for the combined prevalence of engaging in two behavioral strategies for reducing the risk for chronic disease: consuming fruits and vegetables five or more times per day and engaging in regular physical activity. Results were presented for the state of California as a whole and for Californians at or below $130 \%$ FPL. Of all Californians surveyed, $16.3 \%$ of them achieved both strategies, and $16.4 \%$ of those at or below $130 \%$ FPL also achieved both strategies, with significantly higher rates among women than men. These rates and the gender difference are similar to the rate published in the MMWR report, indicating that $14.6 \%$ of U.S. adults engaged in both of these activities. Thus, this report for California, in combination with the report for the nation, demonstrate that most adults are missing the chronic disease prevention opportunity offered by combining healthy eating and physical activity strategies. The finding that Black women across all income levels had a significantly lower prevalence than White women in combining both strategies was also similar to national findings that cite ethnic differences in combining these strategies (Kruger et al., 2007).

For low-income Californians there were no gender or racial/ethnic differences in the combined behavior, but there were differences in the behaviors examined individually. The gender difference in fruit and vegetable consumption was even stronger among the very low-income Californians than in the "all income group," and their consumption was greater than that of their higher income counterparts. Direct attribution of the intervention effect of a broadly diffused public health program, such as the Network, is not the purpose of statewide surveillance surveys. However, the findings in this report do contradict those of the nation at large that show low-income persons consuming fewer fruits and vegetables than others. Although one cannot conclude that strong California public health nutrition education programs, such as the Network and the Women, Children, and Infant's Supplemental Food Program (WIC), that direct their messages to low-income women, positively affected their fruit and vegetable consumption, the findings do suggest that this could be true.

The results that White women were more likely than other groups to achieve physical activity recommendations were consistent with national findings (Kruger and Miles, 2007)

One limitation of the study is the small sample size of subgroups, particularly among persons at or below $130 \%$ FPL. Some estimated differences that were not statistically significant may have been significant if the sample size was larger. Another limitation is that the BRFSS is based on self reports, and thus is subject to reporting errors; a limitation it shares with virtually all nationwide and statewide surveillance systems that monitor diet and physical activity. In addition, because it does not include persons who do not have land-line telephones and who are not institutionalized, the prevalence estimate might be biased to the extent that these groups have different reporting patterns. Also, because the BRFSS is a cross-sectional study, we cannot infer causality from the results.

Finally, fruit and vegetable consumption is reported in terms of "times per day," rather than "servings per day" for BRFSS. Unlike other surveillance systems, such as NHIS (Thompson et al., 2005) and CHIS (Holtby, 2008), BRFSS does not take into account gender or age differences in portion size. Consequently, the percent five a day consumption levels from the BRFSS appear to be considerably lower and show different gender patterns than those observed in the other surveillance surveys that use a more complex algorithm to calculate servings. However, since both the Kruger study and this study used the BRFSS, this limitation would not contribute towards any differences in findings between these studies. Findings were similar for fruit and vegetable consumption in both studies. 
Some populations showed better achievement of individual recommendations than others. Nevertheless, the overall low percentage of adult Californians who concurrently reached both recommended dietary and physical activity behaviors underscores the continued need to promote healthy diets high in fruits and vegetables and regular physical activity among all adult populations in California, regardless of gender, ethnicity, or income. The potential positive effects of increased attainment of these combined goals speak to the significance of this undertaking. No single approach is sufficient to counter the societal influences that operate to encourage adults to choose unhealthy foods and sedentary entertainment. Mass media promotion of healthy lifestyles, direct nutrition education programming and physical activity promotion, innovative systems, public policy, and environmental change approaches that foster increased opportunities for access and availability to healthy food choices and physical activity, and ongoing outreach efforts in the places where people work, shop, play, and worship are all elements of a system that can help California adults reach and maintain optimal health.

\section{References}

The American Association for Public Opinion Research. (2006). Standard Definitions Final Dispositions of Case Codes and Outcome Rates for Surveys. Retrieved February 28, 2009 from www.aapor.org/uploads/standarddefs_4.pdf

Blanck, M., Galuska A., Gillespie, C., Khan, K., Serdula, K., Solera, K., Mokdad, H., \& Cohen, P. (2007). Fruit and vegetable consumption among Adults --- United States, 2005. MMWR, 56, $213-$ 217.

Centers for Disease Control and Prevention. (2009). National Center for Health Statistics. Health Data Interactive. Physical activity, age 18+: U.S., 2004-2006, (Source: National Health Interview Survey). Retrieved February 28, 2009 from www.cdc.gov/nchs/hdi.htm

Cho, E., Seddon, M., Rosner, B., Willett, C., \& Hankinson, E. (2004). Prospective study of intake of fruits, vegetables, vitamins, and carotenoids and risk of age-related maculopathy. Archive of Ophthalmology, 122, 883-892.

Dauchet, L., Amouyel, P., \& Dallongeville, J. (2005). Fruit and vegetable consumption and risk of stroke: a meta-analysis of cohort studies. Neurology, 65, 1193-1197.

He, J., Nowson, A., Lucas, M., \& MacGregor, A. (2007). Increased consumption of fruit and vegetables is related to a reduced risk of coronary heart disease: meta-analysis of cohort studies. Journal of Human Hypertension, 21, 717-728. E-publication 2007, Apr 19.

Holtby, S., Zahnd, E., Chia, J., Lordi, N., Grant. D., \& Rao, M. (2008). Health of California's adults, adolescents and children: Findings from CHIS 2005 and CHIS 2003. Los Angeles, CA: UCLA Center for Health Policy Research.

Kruger, J., \& Miles, I. (2007). Prevalence of regular physical activity among adults-United States, 2001 and 2005. MMWR, 56, 1209-1212.

Kruger, J., Yore, M., Solera, M., \& Moeti, R. (2007). Prevalence of fruit and vegetable consumption and physical activity. $M M W R, 56,301-304$.

Montonen, J., Järvinen, R., Heliövaara, M., \& Reunanen, A., Aromaa, A., \& Knekt, P. (2005). Food consumption and the incidence of type II diabetes mellitus. European Journal of Clinical Nutrition, 59, 441-448.

The National Archives. (2009). Annual Update of the HHS Poverty Guidelines. Federal Register, 71, 3848-3849

National Center for Chronic Disease Prevention and Health Promotion. (2007) Research to Practice Series \#1 - Can Eating Fruits and Vegetables Help People Manage Their Weight? Retrieved February 28, 2009 from http://www.cdc.gov/nccdphp/dnpa/nutrition/pdf/rtp_practitioner_10_07.pdf 
U.S. Department of Health and Human Services Physical Activity Guidelines Advisory Committee. (2008) Physical Activity Guidelines Advisory Committee Report, 2008. Washington, DC: U.S. Department of Health and Human Services.

SAS Institute Inc. (2007). Cary, NC, USA, SAS OnlineDoc® 9.1.3, SAS/STAT User's guide, survey logistic procedure.

Shah, V., Barnwell, G., \& Bieler, S. (1996). SUDAAN: Software for the Statistical Analysis of Correlated Data. User's Manual Release 7.0. Research Triangle Park, NC: Research Triangle Institute.

Svetkey, P., Simons-Morton, D., Vollmer, M., Appel, J., Conlin, R., Ryan, D., Ard, J., \& Kennedy, M. (1999). Effects of dietary patterns on blood pressure: subgroup analysis of the Dietary Approaches to Stop Hypertension (DASH) randomized clinical trial. Archive of Internal Medicine, 159, 285-293.

Thompson, F., Midthune, D., Subar, F., McNeel, T., Berrigan, D., \& Kipnis, V. (2005). Dietary intake estimates in the National Health Interview Survey, 2000: Methodology, results, and interpretation. Journal of American Dietary Association, 105, 352-363.

U.S. Census Bureau (2009). State and County QuickFacts. California and United States. Retrieved February 28, 2009 from http://quickfacts.census.gov/qfd/states/06000.html

World Cancer Research Fund/American Institute for Cancer Research. (2007). Food, Nutrition, Physical Activity, and the Prevention of Cancer: a Global Perspective. Washington DC: American Institute for Cancer Research.

Author Information

Joan Faith Epstein, M.S.*

Survey Research Group,

Cancer Surveillance \& Research Branch;

California Dept of Public Health, Public Health Institute

1825 Bell Street, Suite 102

Sacramento, CA 95825, USA.

Telephone: (916) 779-0114

Email: jepstein@ccr.ca.gov

Sharon B. Sugerman, MS, RD

Network for a Healthy California, Cancer Control Branch;

California Dept of Public Health, Public Health Institute

Patrick Mitchell Dr PH, MA

Network for a Healthy California, Cancer Control Branch;

California Dept of Public Health, Public Health Institute

Marta Induni, PhD

Mathematica, Policy Research, Inc

* corresponding author 


\section{Appendix A}

Table 1. Distribution of the Study Sample by Age, Race and Sex

\begin{tabular}{|c|c|c|c|c|c|}
\hline \multicolumn{6}{|c|}{ Total (Males \& Females) } \\
\hline Age group & WHITE & BLACK & HISPANIC & OTHER & TOTAL \\
\hline \multirow[t]{2}{*}{$18-29$} & 613 & 68 & 670 & 132 & 1483 \\
\hline & $5.2 \%$ & $0.6 \%$ & $5.7 \%$ & $1.1 \%$ & $12.6 \%$ \\
\hline \multirow[t]{2}{*}{ 30-39 } & 996 & 90 & 847 & 200 & 2133 \\
\hline & $8.5 \%$ & $0.8 \%$ & $7.2 \%$ & $1.7 \%$ & $18.1 \%$ \\
\hline \multirow[t]{2}{*}{ 40-49 } & 1428 & 122 & 627 & 214 & 2391 \\
\hline & $12.1 \%$ & $1.0 \%$ & $5.3 \%$ & $1.8 \%$ & $20.3 \%$ \\
\hline \multirow[t]{2}{*}{ 50-59 } & 1644 & 112 & 372 & 139 & 2267 \\
\hline & $13.9 \%$ & $1.0 \%$ & $3.2 \%$ & $1.2 \%$ & $19.2 \%$ \\
\hline \multirow[t]{2}{*}{$60+$} & 2910 & 125 & 351 & 130 & 3516 \\
\hline & $24.7 \%$ & $1.1 \%$ & $3.0 \%$ & $1.1 \%$ & $29.8 \%$ \\
\hline \multirow[t]{2}{*}{ Total } & 7591 & 517 & 2867 & 815 & 11790 \\
\hline & $64.4 \%$ & $4.4 \%$ & $24.3 \%$ & $6.9 \%$ & $100.0 \%$ \\
\hline \multicolumn{6}{|c|}{ Males } \\
\hline Age group & WHITE & BLACK & HISPANIC & OTHER & TOTAL \\
\hline \multirow[t]{2}{*}{ 18-29 } & 257 & 21 & 277 & 63 & 618 \\
\hline & $5.5 \%$ & $0.5 \%$ & $0.6 \%$ & $1.4 \%$ & $13.3 \%$ \\
\hline \multirow[t]{2}{*}{ 30-39 } & 393 & 25 & 333 & 83 & 834 \\
\hline & $8.4 \%$ & $0.5 \%$ & $7.1 \%$ & $1.8 \%$ & $17.9 \%$ \\
\hline \multirow[t]{2}{*}{ 40-49 } & 562 & 44 & 234 & 112 & 952 \\
\hline & $12.1 \%$ & $0.9 \%$ & $5.0 \%$ & $2.4 \%$ & $20.4 \%$ \\
\hline \multirow[t]{2}{*}{ 50-59 } & 681 & 46 & 148 & 59 & 934 \\
\hline & $14.6 \%$ & $1.0 \%$ & $3.2 \%$ & $1.3 \%$ & $20.0 \%$ \\
\hline \multirow[t]{2}{*}{$60+$} & 1108 & 42 & 125 & 49 & 1324 \\
\hline & $23.8 \%$ & $0.9 \%$ & $2.7 \%$ & $1.1 \%$ & $28.4 \%$ \\
\hline \multirow[t]{2}{*}{ Total } & 3001 & 178 & 1117 & 366 & 4662 \\
\hline & $64.4 \%$ & $3.8 \%$ & $24.0 \%$ & $7.9 \%$ & $100.0 \%$ \\
\hline \multicolumn{6}{|c|}{ Females } \\
\hline Age group & WHITE & BLACK & HISPANIC & OTHER & TOTAL \\
\hline \multirow[t]{2}{*}{ 18-29 } & 356 & 47 & 393 & 69 & 865 \\
\hline & $5.0 \%$ & $0.7 \%$ & $5.5 \%$ & $1.0 \%$ & $12.1 \%$ \\
\hline \multirow[t]{2}{*}{$30-39$} & 603 & 65 & 514 & 117 & 1299 \\
\hline & $8.5 \%$ & $0.9 \%$ & $7.2 \%$ & $1.6 \%$ & $18.2 \%$ \\
\hline \multirow[t]{2}{*}{$40-49$} & 866 & 78 & 393 & 102 & 1439 \\
\hline & $12.2 \%$ & $1.1 \%$ & $5.5 \%$ & $1.4 \%$ & $20.2 \%$ \\
\hline \multirow[t]{2}{*}{$50-59$} & 963 & 66 & 224 & 80 & 1333 \\
\hline & $13.5 \%$ & $0.9 \%$ & $3.1 \%$ & $1.1 \%$ & $18.7 \%$ \\
\hline \multirow[t]{2}{*}{$60+$} & 1802 & 83 & 226 & 81 & 2192 \\
\hline & $25.3 \%$ & $1.2 \%$ & $3.2 \%$ & $1.1 \%$ & $30.8 \%$ \\
\hline \multirow[t]{2}{*}{ Total } & 4590 & 339 & 1750 & 449 & 7128 \\
\hline & $64.4 \%$ & $4.8 \%$ & $24.6 \%$ & $6.3 \%$ & $100.0 \%$ \\
\hline
\end{tabular}




\section{Appendix B}

Table 2.

Prevalence of selected levels of fruit and vegetable consumption and physical activity, by sex and race/ethnicity Behavioral Risk Factor Surveillance System, California, 2005 and 2006 Age Adjusted

\begin{tabular}{|c|c|c|c|c|c|c|c|c|c|c|c|}
\hline & \multirow{2}{*}{$\mathbf{N}$} & \multicolumn{2}{|c|}{ Total } & \multicolumn{2}{|c|}{ White } & \multicolumn{2}{|c|}{ Black } & \multicolumn{2}{|c|}{ Hispanic } & \multicolumn{2}{|c|}{ Other } \\
\hline & & $\%$ & $95 \% \mathrm{CI}$ & $\%$ & $95 \% \mathrm{CI}$ & $\%$ & $95 \%$ CI & $\%$ & $95 \% \mathrm{CI}$ & $\%$ & $95 \%$ CI \\
\hline \multicolumn{12}{|l|}{ Fruit \& Vegetables } \\
\hline$<5$ & 6864 & 73.4 & $70.1-76.8$ & 75.2 & $71.9-78.5$ & 76.7 & $62.5-91.0$ & 74.5 & $68.9-80.1$ & 65.1 & $50.3-79.9$ \\
\hline$\geq 5$ & 3035 & 26.6 & $23.2-29.9$ & 24.8 & $21.5-28.1$ & 23.3 & $9.0-37.5$ & 25.5 & 19.9-31.1 & 34.9 & $20.1 .-49.7$ \\
\hline \multicolumn{12}{|l|}{ Physical Activity } \\
\hline Regular & 5327 & 52.7 & $48.2-57.2$ & $58.5^{\mathrm{c}}$ & $54.1-63.0$ & 66.4 & $46.5-86.3$ & $45.6^{\mathrm{c}}$ & $38.6-52.5$ & 46.0 & $29.3-62.8$ \\
\hline Insufficiently active & 3795 & 32.0 & $28.4-35.5$ & 32.6 & $28.4-36.7$ & 24.1 & $8.8 .-39.3$ & 33.0 & $27.1-39.0$ & 30.9 & $18.0-43.8$ \\
\hline Inactive & 1257 & 15.3 & $10.7-19.9$ & 8.9 & $6.6-11.3$ & 9.6 & $3.3-15.8$ & 21.4 & $15.8-27.0$ & 23.1 & $0.0-46.3$ \\
\hline \multicolumn{12}{|l|}{ Combined } \\
\hline$\geq 5 \&$ regular active & 1940 & 16.3 & 13.6-19.1 & 17.3 & $14.4-20.1$ & 13.5 & $3.9-23.1$ & 13.1 & $8.6-17.5$ & 21.4 & $9.6-33.2$ \\
\hline$\geq 5 \&$ not regular active & 1072 & 10.2 & $8.2-12.3$ & 7.5 & $5.9-9.1$ & 9.0 & $2.9-15.0$ & 12.6 & $8.6-16.6$ & 13.6 & $4.6-22.6$ \\
\hline Not $\geq 5$ and regular active & 3387 & 37.1 & $32.7-41.5$ & 42.0 & $37.1-46.8$ & 53.3 & 26.4-80.1 & 33.1 & $26.0-40.1$ & 25.5 & $13.8-37.1$ \\
\hline Not $\geq 5$ and not regular active & 3403 & 36.4 & $31.8-40.9$ & 33.3 & $29.0-37.6$ & $24.3^{\mathrm{n}}$ & $8.9-39.7$ & $41.2^{\mathrm{n}}$ & $34.6-47.9$ & 39.5 & $19.6-59.5$ \\
\hline
\end{tabular}

\begin{tabular}{|c|c|c|c|c|c|c|c|c|c|c|c|}
\hline \multicolumn{12}{|c|}{ Males } \\
\hline & \multirow{2}{*}{$\mathbf{N}$} & \multicolumn{2}{|c|}{ Total } & \multicolumn{2}{|c|}{ White } & \multicolumn{2}{|c|}{ Black } & \multicolumn{2}{|c|}{ Hispanic } & \multicolumn{2}{|c|}{ Other } \\
\hline & & $\%$ & $95 \%$ CI & $\%$ & $95 \%$ CI & $\%$ & 95\% CI & $\%$ & 95\% CI & $\%$ & $95 \%$ CI \\
\hline \multicolumn{12}{|l|}{ Fruit \& Vegetables } \\
\hline$<5$ & 2971 & 78.8 & $74.5-83.2$ & 81.2 & $77.3-85.0$ & 81 & $62.5-99.6$ & 82.1 & $77.8-90.3$ & 62.3 & $45.2-79.3$ \\
\hline$\geq 5$ & 921 & $21.2^{1}$ & $16.9-25.5$ & $18.8^{2 \mathrm{a}}$ & $15.0-22.7$ & 19 & $0.4-37.5$ & $17.9^{3 \mathrm{~b}}$ & $11.1-24.7$ & $37.7^{\mathrm{ab}}$ & $20.7-54.8$ \\
\hline \multicolumn{12}{|l|}{ Physical Activity } \\
\hline Regular & 2076 & 54.6 & $48.7-60.4$ & $56.7^{\mathrm{de}}$ & $50.4-63.0$ & $79.8^{\mathrm{d}}$ & $60.3-99.3$ & $43.5^{\mathrm{e}}$ & $33.2-53.9$ & $64.7^{4}$ & $50.9-78.5$ \\
\hline Insufficiently active & 1531 & 30.8 & $26.0-35.6$ & 32.2 & $26.4-37.9$ & 14.8 & $0.0-30.2$ & 32.2 & $23.5-41.0$ & 31.3. & $18.3-44.4$ \\
\hline Inactive & 479 & 14.6 & $10.7-18.5$ & 11.1 & $7.5-14.7$ & $5.4^{*}$ & $0.0-10.9$ & 24.3 & $15.4-33.1$ & 3.9 & $1.1-6.8$ \\
\hline \multicolumn{12}{|l|}{ Combined } \\
\hline$\geq 5 \&$ regularly active & 589 & $13.4^{5}$ & $9.6-17.2$ & $12.4^{6}$ & $9.4-15.5$ & $13.6^{*}$ & $0.0-28.2$ & 9.5 & $4.02-14.9$ & 26.6 & $8.9-44.4$ \\
\hline$\geq 5 \&$ not regularly active & 319 & 7.7 & $5.6-9.9$ & 6.5 & $4.3-8.7$ & 3.9 & $0.0-8.5$ & 8.4 & $\begin{array}{l}4.00- \\
12.90\end{array}$ & 11.3 & $3.7-18.8$ \\
\hline Not $\geq 5$ and regularly active & 1487 & 41.9 & $35.5-48.4$ & 45.2 & $38.4-51.9$ & 66.3 & $35.4-97.1$ & 34.8 & $24.2-45.3$ & 38.8 & $22.2-55.4$ \\
\hline Not $\geq 5$ and not regularly active & 1455 & 37.0 & $31.5-42.5$ & $35.9^{\mathrm{f}}$ & $29.8-42.0$ & $\begin{array}{l}16.3 \\
7 \text { fghi }\end{array}$ & $0.00-32.7$ & $\begin{array}{l}47.3 \\
8 \mathrm{gh}\end{array}$ & $37.1-57.6$ & $23.3^{\text {hi }}$ & $12.2-34.5$ \\
\hline
\end{tabular}

\begin{tabular}{|c|c|c|c|c|c|c|c|c|c|c|c|}
\hline \multicolumn{12}{|c|}{ Females } \\
\hline & \multirow{2}{*}{$\mathbf{N}$} & \multicolumn{2}{|c|}{ Total } & \multicolumn{2}{|c|}{ White } & \multicolumn{2}{|c|}{ Black } & \multicolumn{2}{|c|}{ Hispanic } & \multicolumn{2}{|c|}{ Other } \\
\hline & & $\%$ & $95 \% \mathrm{CI}$ & $\%$ & $95 \% \mathrm{CI}$ & $\%$ & 95\% CI & $\%$ & $95 \%$ CI & $\%$ & $95 \% \mathrm{CI}$ \\
\hline \multicolumn{12}{|l|}{ Fruit \& Vegetables } \\
\hline$<5$ & 3893 & 68.0 & $62.7-73.3$ & 70.1 & $64.9-75.3$ & 69.2 & $58.3-80.1$ & 64.7 & $56.2-73.1$ & 67.3 & $45.3-89.3$ \\
\hline$\geq 5$ & 2114 & $32.0^{1}$ & $26.7-37.3$ & $29.9^{2}$ & $24.7-35.1$ & 30.8 & $19.9-41.7$ & $35.3^{3}$ & $26.9-43.8$ & 32.7 & $7.3-53.6$ \\
\hline \multicolumn{12}{|l|}{ Physical Activity } \\
\hline Regular & 3251 & 50.9 & $44.3-57.5$ & $60.1^{\mathrm{jkl}}$ & $53.8-66.3$ & $43.4^{j}$ & $28.7-58.1$ & $48.3^{\mathrm{k}}$ & $39.6-56.8$ & $31.4^{41}$ & $11.7-51.1$ \\
\hline Insufficiently active & 2264 & 33.1 & $26.8-38.4$ & 32.9 & $27.0-38.8$ & 39.9 & $25.2-54.5$ & 34.1 & $26.5-41.7$ & 30.5 & $10.1-51.0$ \\
\hline Inactive & 778 & 16.0 & $7.7-24.3$ & 7.0 & $3.9-10.1$ & 16.7 & $8.9-24.5$ & 17.6 & $12.0-23.3$ & 38.1 & $4.4-72.0$ \\
\hline \multicolumn{12}{|l|}{ Combined } \\
\hline$\geq 5$ and regularly active & 1351 & $19.3^{5}$ & $15.3-23.3$ & $21.4^{6 \mathrm{~m}}$ & $16.7-26.0$ & $13.4^{\mathrm{m}}$ & $6.9-19.9$ & 17.8 & $10.6-24.9$ & 17.2 & $3.5-31.0$ \\
\hline$\geq 5$ and not regularly active & 753 & 12.8 & $9.3-16.3$ & 8.4 & $6.1-10.6$ & 17.7 & $9.4-25.9$ & 18.1 & $11.3-24.9$ & 15.5 & $0.2-30.7$ \\
\hline Not $\geq 5$ and regularly active & 1900 & 32.2 & $26.6-37.7$ & 39.2 & $32.4-46.1$ & 30.7 & $15.5-45.9$ & 30.9 & $22.3-39.5$ & 14.9 & $4.3-25.6$ \\
\hline Not $\geq 5$ and not regularly active & 1948 & 35.7 & $28.4-43.1$ & 31.0 & $25.0-37.1$ & $38.2^{7}$ & $23.3-53.0$ & $33.2^{8}$ & $26.1-40.3$ & 52.4 & $24.3-80.4$ \\
\hline
\end{tabular}

* Cells with fewer than 30 cases

${ }^{1-8}$ Number superscripted variables differ significantly $(p \leq .05)$ by Gender with the same superscript.

${ }^{a-n}$ Letter superscripted variables differ significantly $(p \leq .05)$ by Ethnicity with the same superscript. 


\section{Appendix C}

Table 3.

Prevalence of selected levels of fruit and vegetable consumption and physical activity, by sex and race/ethnicity for persons $\leq 130 \%$ of poverty level -Behavioral Risk Factor Surveillance System, California, 2005-2006

\begin{tabular}{|c|c|c|c|c|c|c|c|}
\hline & & \multicolumn{2}{|r|}{ Total } & \multicolumn{2}{|r|}{ White } & \multicolumn{2}{|c|}{ Non-White } \\
\hline & $\mathbf{N}$ & $\%$ & $95 \% \mathrm{CI}$ & $\%$ & $95 \% \mathrm{CI}$ & $\%$ & $95 \% \mathrm{CI}$ \\
\hline \multicolumn{8}{|l|}{ Fruit \& Vegetables } \\
\hline$<5$ & 1143 & 66.6 & $58.3-74.9$ & 72.0 & $58.0-85.9$ & 65.2 & $55.4-75.0$ \\
\hline$\geq 5$ & 443 & 33.4 & $25.1-41.7$ & 28.0 & $14.1-42.0$ & 34.8 & $25.0-44.6$ \\
\hline \multicolumn{8}{|l|}{ Physical Activity } \\
\hline Regular & 712 & 46.6 & $38.2-55.0$ & 52.8 & $39.4-66.3$ & 45.0 & $34.9-55.0$ \\
\hline Insufficiently active & 610 & 31.1 & $24.6-37.7$ & 26.6 & $16.8-36.4$ & 32.3 & $24.4-40.2$ \\
\hline Inactive & 367 & 22.3 & $16.0-28.6$ & 20.5 & $9.1-32.0$ & 22.7 & $15.3-30.1$ \\
\hline \multicolumn{8}{|l|}{ Combined } \\
\hline$\geq 5$ and regular active & 241 & 16.4 & $8.6-24.2$ & 17.2 & $3.7-30.6$ & 16.2 & $7.0-25.4$ \\
\hline$\geq 5$ and not regular active & 197 & 17.1 & $11.4-22.9$ & 10.9 & $3.1-18.7$ & 18.8 & $11.8-25.7$ \\
\hline Not $\geq 5$ and regular active & 471 & 30.8 & $22.8-38.8$ & 36.9 & $23.7-50.0$ & 29.2 & $19.7-38.8$ \\
\hline Not $\geq 5$ and not regular active & 657 & 35.7 & $28.5-42.9$ & 35.1 & $22.6-47.6$ & 35.9 & $27.4-44.3$ \\
\hline
\end{tabular}

\begin{tabular}{|c|c|c|c|c|c|c|c|}
\hline \multicolumn{8}{|c|}{ Males } \\
\hline & \multirow{2}{*}{$\mathbf{N}$} & \multicolumn{2}{|r|}{ Total } & \multicolumn{2}{|r|}{ White } & \multicolumn{2}{|c|}{ Non-White } \\
\hline & & $\%$ & $95 \% \mathrm{CI}$ & $\%$ & $95 \% \mathrm{CI}$ & $\%$ & $95 \% \mathrm{CI}$ \\
\hline \multicolumn{8}{|l|}{ Fruit \& Vegetables } \\
\hline$<5$ & 423 & 74.3 & $62.0-86.6$ & 74.9 & $59.0-90.9$ & 74.2 & $59.7-88.6$ \\
\hline$\geq 5$ & 131 & $25.7^{1}$ & $13.4-38.0$ & 25.1 & $9.1-41.0$ & 25.8 & $11.4-40.2$ \\
\hline \multicolumn{8}{|l|}{ Physical Activity } \\
\hline Regular & 243 & 46.9 & $33.5-60.3$ & 41.1 & $24.1-58.0$ & 48.2 & $32.5-63.8$ \\
\hline Insufficiently active & 223 & 29.6 & $20.0-39.3$ & 29.5 & $14.3-44.7$ & 29.7 & $18.4-40.9$ \\
\hline Inactive & 129 & 23.5 & $13.6-33.3$ & 29.4 & $8.3-50.6$ & 22.2 & $11.4-33.0$ \\
\hline \multicolumn{8}{|l|}{ Combined } \\
\hline$\geq 5$ and regularly active & 74 & 13.2 & $1.2-25.2$ & $8.3 *$ & $0.1-16.4$ & 14.3 & $0.00-28.6$ \\
\hline$\geq 5$ and not regularly active & 54 & 12.6 & $6.4-18.8$ & 16.8 & $2.0-31.6$ & 11.7 & $5.0-18.3$ \\
\hline Not $\geq 5$ and regularly active & 169 & 34.2 & $20.7-47.7$ & 33.0 & $17.7-48.4$ & 34.5 & $18.4-50.5$ \\
\hline Not $\geq 5$ and not regularly active & 251 & 40.0 & $28.1-52.0$ & 41.9 & $22.5-36.2$ & 39.6 & $25.8-53.5$ \\
\hline
\end{tabular}

\begin{tabular}{|c|c|c|c|c|c|c|c|}
\hline \multicolumn{8}{|c|}{ Females } \\
\hline & \multirow{2}{*}{$\mathbf{N}$} & \multicolumn{2}{|r|}{ Total } & \multicolumn{2}{|r|}{ White } & \multicolumn{2}{|c|}{ Non-White } \\
\hline & & $\%$ & 95\% CI & $\%$ & $95 \% \mathrm{CI}$ & $\%$ & $95 \% \mathrm{CI}$ \\
\hline \multicolumn{8}{|l|}{ Fruit \& Vegetables } \\
\hline$<5$ & 720 & 58.6 & $48.1-69.2$ & 69.7 & $48.6-90.8$ & 55.3 & $43.3-67.2$ \\
\hline$\geq 5$ & 312 & $41.4^{1}$ & $30.8-51.9$ & 30.3 & $9.2-51.4$ & 44.7 & $32.8-56.7$ \\
\hline \multicolumn{8}{|l|}{ Physical Activity } \\
\hline Regular & 469 & 46.2 & $36.4-56.2$ & $61.7^{\mathrm{a}}$ & $45.4-78.1$ & $41.4^{\mathrm{a}}$ & $30.1-52.7$ \\
\hline Insufficiently active & 387 & 32.7 & $23.9-41.4$ & 24.4 & $11.9-37.0$ & 35.3 & $24.7-45.9$ \\
\hline Inactive & 238 & 21.0 & $13.1-28.9$ & 13.8 & $4.9-22.7$ & 23.3 & $13.5-33.1$ \\
\hline \multicolumn{8}{|l|}{ Combined } \\
\hline$\geq 5$ and regularly active & 167 & 19.7 & $9.7-29.7$ & 24.1 & $2.5-45.6$ & 18.3 & $7.1-29.3$ \\
\hline$\geq 5$ and not regularly active & 143 & 21.8 & $12.6-31.1$ & 6.3 & $0.0-13.0$ & 26.6 & $15.2-38.0$ \\
\hline Not $\geq 5$ and regularly active & 302 & 27.3 & $19.4-35.2$ & 39.9 & $20.1-59.7$ & 23.4 & $15.6-31.3$ \\
\hline Not $\geq 5$ and not regularly active & 406 & 31.2 & $23.3-39.2$ & 29.8 & $15.5-44.1$ & 31.7 & $22.3-41.1$ \\
\hline
\end{tabular}

${ }^{1}$ Number superscripted variables differ significantly $(\mathrm{p} \leq .05)$ by Gender with the same superscript.

${ }^{a}$ Letter superscripted variables differ significantly $(\mathrm{p} \leq .05)$ by Ethnicity with the same superscript.

* Cells with fewer than 30 cases 


\section{Appendix D}

Table 4.

Prevalence of selected levels of fruit and vegetable consumption and physical activity, by sex and race/ethnicity for persons $>130 \%$ of poverty level - Behavioral Risk Factor Surveillance System, California, 2005-2006

\begin{tabular}{|c|c|c|c|c|c|c|c|}
\hline \multicolumn{8}{|c|}{ Total (Males \& Females) } \\
\hline & $\mathbf{N}$ & \multicolumn{2}{|r|}{ Total } & \multicolumn{2}{|r|}{ White } & \multicolumn{2}{|c|}{ Non-White } \\
\hline \multicolumn{8}{|l|}{ Fruit \& Vegetables } \\
\hline$\geq 5$ & 2328 & 24.2 & $20.5-27.9$ & 23.9 & $20.5-27.3$ & 24.5 & $17.7-31.3$ \\
\hline \multicolumn{8}{|l|}{ Physical Activity } \\
\hline Regular & 4677 & 55.1 & $49.5-60.7$ & $60.1^{\mathrm{b}}$ & $55.3-64.8$ & $49.6^{\mathrm{b}}$ & $39.3-59.8$ \\
\hline \multicolumn{8}{|l|}{ Combined } \\
\hline$\geq 5$ and regular active & 1543 & 16.1 & $13.2-19.0$ & 17.0 & $14.1-20.0$ & 15.1 & $10.0-20.1$ \\
\hline$\geq 5$ and not regular active & 770 & 8.1 & $5.9-10.3$ & 6.8 & $5.4-8.3$ & 9.4 & $5.0-13.8$ \\
\hline Not $\geq 5$ and regular active & 2718 & 38.9 & $33.4-44.5$ & 43.0 & $37.7-48.4$ & 34.3 & $24.5-44.2$ \\
\hline Not $\geq 5$ and not regular active & 2538 & 36.9 & $31.1-42.7$ & 33.1 & $28.5-37.7$ & 41.2 & $30.3-52.1$ \\
\hline
\end{tabular}

\begin{tabular}{|c|c|c|c|c|c|c|c|}
\hline \multicolumn{8}{|c|}{ Males } \\
\hline & $\mathbf{N}$ & \multicolumn{2}{|r|}{ Total } & \multicolumn{2}{|r|}{ White } & \multicolumn{2}{|c|}{ Non-White } \\
\hline \multicolumn{8}{|l|}{ Fruit \& Vegetables } \\
\hline$\geq 5$ & 734 & $19.5^{1}$ & $15.2-24.0$ & $18.0^{2}$ & $14.0-21.9$ & 20.9 & $13.1-28.7$ \\
\hline \multicolumn{8}{|l|}{ Physical Activity } \\
\hline Regular & 1915 & 57.3 & $50.6-63.9$ & $57.6^{3}$ & $50.8-64.4$ & 56.9 & $45.6-68.2$ \\
\hline \multicolumn{8}{|l|}{ Combined } \\
\hline$\geq 5$ and regularly active & 487 & 13.4 & $9.7-17.1$ & 12.4 & $9.1-15.7$ & 14.2 & $7.7-20.7$ \\
\hline$\geq 5$ and not regularly active & 247 & 6.1 & $3.8-8.5$ & 5.5 & $3.6-7.4$ & 6.7 & $2.5-10.9$ \\
\hline Not $\geq 5$ and regularly active & 1237 & 43.8 & $36.2-51.5$ & 45.3 & $37.8-52.9$ & 42.5 & $29.4-55.5$ \\
\hline Not $\geq 5$ and not regularly active & 1141 & 36.7 & $30.2-43.2$ & 36.7 & $30.0-43.5$ & 36.6 & $25.7-47.5$ \\
\hline
\end{tabular}

\begin{tabular}{|c|c|c|c|c|c|c|c|}
\hline \multicolumn{8}{|c|}{ Females } \\
\hline & \multirow{2}{*}{$\mathbf{N}$} & \multicolumn{2}{|r|}{ Total } & \multicolumn{2}{|r|}{ White } & \multicolumn{2}{|c|}{ Non-White } \\
\hline & & $\%$ & $95 \% \mathrm{CI}$ & $\%$ & $95 \% \mathrm{CI}$ & $\%$ & $95 \% \mathrm{CI}$ \\
\hline \multicolumn{8}{|l|}{ Fruit \& Vegetables } \\
\hline$\geq 5$ & 1579 & $29.1^{1}$ & $22.9-35.2$ & $29.1^{2}$ & $23.7-34.5$ & 29.2 & $16.5-41.8$ \\
\hline \multicolumn{8}{|l|}{ Physical Activity } \\
\hline Inactive & 468 & 15.0 & $3.4-26.7$ & 6.1 & $2.5-9.6$ & 27.5 & $3.8-51.1$ \\
\hline \multicolumn{8}{|l|}{ Combined } \\
\hline$\geq 5$ and regularly active & 1056 & 19.0 & $14.4-23.6$ & 21.1 & $16.3-25.8$ & 16.1 & $8.0-24.3$ \\
\hline$\geq 5$ and not regularly active & 523 & 10.1 & $6.3-14.0$ & 8.0 & $5.8-10.3$ & 13.0 & $4.3-21.8$ \\
\hline Not $\geq 5$ and regularly active & 1481 & 33.7 & $26.5-40.9$ & 41.0 & $33.4-48.7$ & 23.7 & $13.2-34.2$ \\
\hline Not $\geq 5$ and not regularly active & 1397 & 37.2 & $27.4-47.0$ & 29.9 & $23.5-36.2$ & 47.1 & $28.4-65.9$ \\
\hline
\end{tabular}

${ }^{1}$ Number superscripted variables differ significantly $(\mathrm{p} \leq .05)$ by Gender with the same superscript.

${ }^{a}$ Letter superscripted variables differ significantly $(\mathrm{p} \leq .05)$ by Ethnicity with the same superscript. 